\title{
Sample Size for Oxidative Stress and Inflammation When Treating Multiple Sclerosis with Interferon- $\beta 1 a$ and Coenzyme Q10
}

\author{
Marcello Moccia 1,*(1), Antonio Capacchione ${ }^{2}$, Roberta Lanzillo ${ }^{1}$, Fortunata Carbone ${ }^{3,4}$, \\ Teresa Micillo $^{5}$, Giuseppe Matarese ${ }^{4,6}$, Raffaele Palladino ${ }^{7,8}$ (D) and Vincenzo Brescia Morra ${ }^{1}$ \\ 1 Multiple Sclerosis Clinical Care and Research Centre, Department of Neuroscience, Reproductive Science \\ and Odontostomatology, Federico II University, 80131 Naples, Italy; robertalanzillo@libero.it (R.L.); \\ vincenzo.bresciamorra2@unina.it (V.B.M.) \\ 2 Medical Affairs Department, Merck, 00176 Rome, Italy; antonio.capacchione@merckgroup.com \\ 3 Neuroimmunology Unit, IRCCS Fondazione Santa Lucia, 00142 Rome, Italy; fortunata.carbone@alice.it \\ 4 Laboratory of Immunology, Institute of Experimental Endocrinology and Oncology, National Research \\ Council (IEOS-CNR), 80131 Naples, Italy; giuseppe.matarese@unina.it \\ 5 Department of Biology, Federico II University, 80131 Naples, Italy; teresa.micillo2@unina.it \\ 6 Treg Cell Lab, Department of Molecular Medicine and Medical Biotechnologies, Federico II University, \\ 80131 Naples, Italy \\ 7 Department of Primary Care and Public Health, Imperial College, London W68RP, UK; \\ palladino.raffaele@gmail.com \\ 8 Department of Public Health, Federico II University, 80131 Naples, Italy \\ * Correspondence: moccia.marcello@gmail.com; Tel./Fax: +39-0817462670
}

Received: 23 August 2019; Accepted: 25 September 2019; Published: 27 September 2019

\begin{abstract}
Studying multiple sclerosis (MS) and its treatments requires the use of biomarkers for underlying pathological mechanisms. We aim to estimate the required sample size for detecting variations of biomarkers of inflammation and oxidative stress. This is a post-hoc analysis on 60 relapsing-remitting MS patients treated with Interferon- $\beta 1$ a and Coenzyme Q10 for 3 months in an open-label crossover design over 6 months. At baseline and at the 3 and 6-month visits, we measured markers of scavenging activity, oxidative damage, and inflammation in the peripheral blood (180 measurements). Variations of laboratory measures (treatment effect) were estimated using mixed-effect linear regression models (including age, gender, disease duration, baseline expanded disability status scale (EDSS), and the duration of Interferon- $\beta 1$ a treatment as covariates; creatinine was also included for uric acid analyses), and were used for sample size calculations. Hypothesizing a clinical trial aiming to detect a $70 \%$ effect in 3 months (power $=80 \%$ alpha-error $=5 \%$ ), the sample size per treatment arm would be 1 for interleukin (IL)-3 and IL-5, 4 for IL-7 and IL-2R, 6 for IL-13, 14 for IL-6, 22 for IL-8, 23 for IL-4, 25 for activation-normal T cell expressed and secreted (RANTES), 26 for tumor necrosis factor (TNF)- $\alpha, 27$ for IL- $1 \beta$, and 29 for uric acid. Peripheral biomarkers of oxidative stress and inflammation could be used in proof-of-concept studies to quickly screen the mechanisms of action of MS treatments.
\end{abstract}

Keywords: multiple sclerosis; inflammation; oxidative; biomarker; sample size

\section{Introduction}

Monitoring multiple sclerosis (MS) and developing new disease modifying treatments (DMTs) requires the use of biomarkers for underlying pathological mechanisms [1,2]. Thus, it is crucial to define a set of biomarkers that can be easily measured (e.g., in accessible body fluids), are quickly responsive to change, and reflect MS clinical features accurately [2,3]. 
Experimental evidence supports the important role of inflammation and oxidative stress in the pathogenesis of MS [4]. In the initial relapsing-remitting (RR) phase, oxidative stress is strictly associated with inflammatory activity, whereas the progressive phase is characterized by chronic inflammation and neurodegeneration, further amplifying the oxidative damage [4,5]. In our recent study [6], supplementation with Coenzyme Q10, a natural anti-oxidant, along with Interferon- $\beta 1 \mathrm{a}$ 44 mcg treatment, was associated with an improved oxidative balance, with a shift toward an anti-inflammatory milieu and with related clinical benefits. However, in this study we used a large number of peripheral biomarkers of oxidative stress and inflammation, which was time-and resource-consuming, and ultimately resulted in a significant statistical challenge due to multiple comparisons [6]. Thus, future studies would benefit from a subset of biomarkers that are sensitive to change in a short time and on a small sample.

In the present post-hoc analysis of our previous longitudinal study, we aim to estimate the sample size needed in RR-MS for different peripheral biomarkers of oxidative stress and inflammation.

\section{Materials and Methods}

\subsection{Study Design and Population}

This is a post-hoc analysis on a prospective cohort that was fully described elsewhere [6]. Briefly, in 2016-2017, we included 60 RRMS patients on clinical stability and on treatment with subcutaneous high-dose Interferon- $\beta 1 \mathrm{a}$ (Rebif ${ }^{\circledR}, 44$ mcg, Merck, Rome, Italy), either alone or with Coenzyme Q10 (Skatto ${ }^{\circledR}, 100 \mathrm{mg} / \mathrm{ml}$, Chiesi Farmaceutici SpA, Parma, Italy) for 3 months, with a cross-over design. In particular, group $1(n=30)$ was treated with Interferon- $\beta 1$ a and Coenzyme Q10 from baseline to a 3 -month visit, and then with Interferon- $\beta 1$ a alone until a 6 -month visit; meanwhile, group $2(n=30)$ was treated with Interferon- $\beta 1$ a alone from baseline to a 3-month visit, and then with Interferon- $\beta 1 \mathrm{a}$ and Coenzyme Q10 until a 6-month visit. This design used within-subjects comparison of treatments, and therefore minimized confounding variables by removing any natural biological variation that may have occurred in the measurement of the outcome measures [6,7].

\subsection{Laboratory Analyses}

Blood samples were collected at baseline and after 3 and 6 months (60 patients with 3 laboratory measurements, with 180 measurements overall) in fasting conditions in lithium heparin tubes, immediately centrifuged, stored at $-80^{\circ} \mathrm{C}$, and then analyzed for:

(1) Markers of free radical scavenging activity: uric acid and bilirubin were measured by using the UA2 and the BILTS enzymatic methods $\left(\mathrm{COBAS}^{\circledR}{ }^{\circledR} 501\right.$ analyser, Roche Diagnostic, Mannheim, Germany);

(2) Markers of serum oxidative damage: 8-hydroxy-2-deoxyguanosine (8-OHdG, an end product of oxidative DNA damage) and protein carbonyls (an end product of oxidative protein damage) were measured by using the OxiSelect ${ }^{\mathrm{TM}}$ Oxidative DNA Damage ELISA kit, and the OxiSelect ${ }^{\mathrm{TM}}$ Protein Carbonyl ELISA Kit (both from Cell Biolabs, San Diego, CA, USA);

(3) Markers of inflammation: the Human Cytokine Magnetic 35-Plex Panel (Invitrogen by Thermo Fisher Scientific, Waltham, MA, USA) was used for the quantitative detection of epidermal growth factor (EGF), eotaxin, basic-fibroblast growth factor (FGF), granulocyte-colony stimulating factor (G-CSF), granulocyte-macrophage colony-stimulating factor (GM-CSF), hepatocyte growth factor (HGF), Interferon (IFN)- $\alpha$, IFN- $\gamma$, interleukin (IL)- $1 \alpha$, IL-1 $\beta$, IL-1RA, IL-2, IL-2R, IL-3, IL-4, IL-5, IL-6, IL-7, IL-8, IL-9, IL-10, IL-12, IL-13, IL-15, IL-17A, IL-17F, IL-22, IFN- $\gamma$-inducible protein (IP)-10, monocyte chemoattractant protein (MCP)-1, monokine induced by IFN- $\gamma$ (MIG), macrophage inflammatory proteins (MIP)- $1 \alpha$, MIP- $1 \beta$, regulated on activation-normal T cell expressed and secreted (RANTES), tumor necrosis factor (TNF)- $\alpha$, and vascular endothelial growth factor (VEGF).

CellROX ${ }^{\circledR}$ Orange Reagent (Life Technologies, Carlsbad, CA, USA) was used for measuring intracellular reactive oxygen species (ROS) production in peripheral blood mononuclear cells (PBMCs) 
using a FACScanto II analyzer (Becton-Dickinson, San Diego, CA, USA) and Flow-Jo v10 software (Tree Star Inc., Ashland, OR, USA); intracellular ROS production (CellROX) was measured as percent positive cells (\%) and mean fluorescence intensity (MFI).

\subsection{Statistics}

The sample size needed to detect a treatment effect on different markers of oxidative stress and inflammation was computed using the formula $n=\frac{2\left(Z_{\alpha}+Z_{1-\beta}\right)^{2} \sigma^{2}}{\Delta^{2}}$, where $n$ is the required sample size per treatment arm in 1:1 controlled trials, $Z_{\alpha}$ and $Z_{1-\beta}$ are constants (set at $5 \%$ alpha-error and $80 \%$ power, respectively), $\sigma$ is the standard deviation, and $\Delta$ the estimated effect size [8,9]. The treatment effect was defined as the actual observed effect in our previous study (i.e., variation in each laboratory measure between treated and untreated groups), estimated using mixed-effect linear regression models (including age, gender, disease duration, baseline expanded disability status scale (EDSS), and duration of Interferon- $\beta 1$ a treatment prior to study inclusion as covariates; creatinine was also included for uric acid analyses) $[6,8,9]$. The crossover model included random effects for patient ID, and fixed-effects for time (baseline, 3 and 6 months), and for the visit after Coenzyme Q10 exposure, overall accounting for possible carry-over effects. Adjusted beta-coefficients of 3-month variations were obtained for each laboratory measure. We assumed that the observed variation, as estimated by the adjusted beta-coefficients, was the highest achievable treatment effect (100\%) over 3 months. From there, with a conservative approach, we hypothesized a number of effect sizes-e.g., 30\%, 50\%, 70\%, and 90\%-that were smaller than the observed effect. Standard deviations were calculated from the variation of each laboratory measure after 3 months. Then, we hypothesized a clinical trial where two different biomarkers were included as primary outcome measures for sample size estimates (alpha-error was set at $2.5 \%$ ). Finally, we considered that the study was designed to include one or two interim analyses in addition to the final analysis (alpha-error was set at $2.94 \%$ and $2.21 \%$, respectively, according to the Pocock method) [10,11].

Stata 15.0 (StataCorp LLC, College Station, TX, USA) was used for data processing and analysis.

\section{Results}

Sixty RRMS patients were included in the present study (age: $41.5 \pm 9.7$ years; female: $n=42$ (70\%); disease duration: $11.0 \pm 1.7$ years; baseline EDSS: 2.5 (1.0-5.0)). Four patients presented with a clinical relapse $(6.6 \%)$ during the study period.

Hypothesizing a clinical trial aiming to detect $70 \%$ effect in 3 months (power $=80 \%$ alpha-error $=$ $5 \%$ ), the sample size per treatment arm would be 1 for IL-3 and IL-5, 4 for IL-7 and IL-2R, 6 for IL-13, 14 for IL-6, 22 for IL-8, 23 for IL-4, 25 for RANTES, 26 for TNF- $\alpha, 27$ for IL-1 $\beta$, and 29 for uric acid (Figure 1, Table 1). Other investigated markers presented with a sample size per treatment arm larger than 30 (Table 1). 


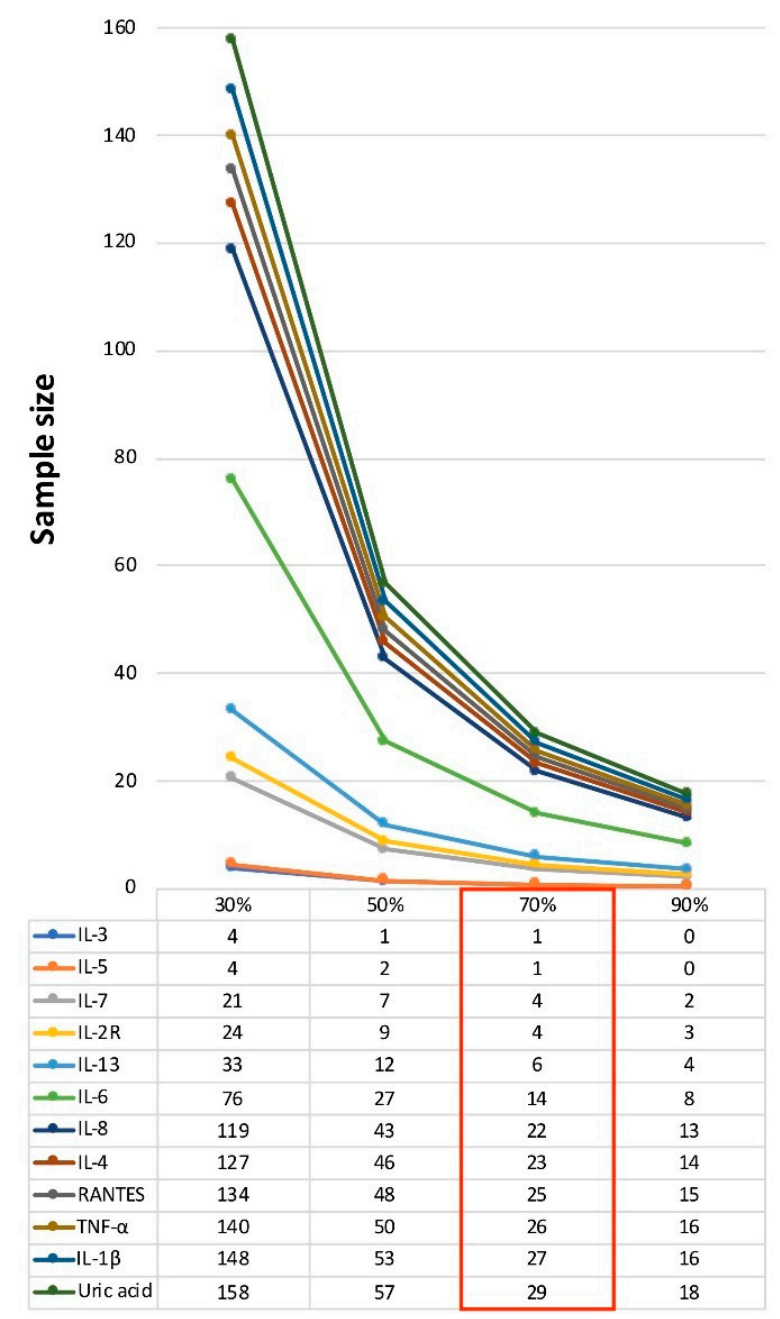

Figure 1. Profile plot for sample size estimates for a treatment arm. Figure shows sample sizes for laboratory markers of oxidative stress and inflammation ( $<30$ patients for a treatment arm with a $70 \%$ treatment effect). Sample size per treatment arm is reported hypothesizing a $30 \%, 50 \%, 70 \%$, and $90 \%$ treatment effect compared with the observed effect. Power was set at $80 \%$ and alpha-error at $5 \%$. Abbreviations: interleukin (IL), regulated on activation-normal $\mathrm{T}$ cell expressed and secreted (RANTES), and tumor necrosis factor (TNF).

Hypothesizing the combination of two different biomarkers as primary outcome measures (alpha-error $=2.5 \%$ ), sample size estimates per treatment arm remained substantially favorable ( 3 for IL-3 and IL-5, 7 for IL-7, 8 for IL-2R, 9 for IL-13, 19 for IL-6, 28 for IL-8, 30 for IL-4, 32 for RANTES, 33 for TNF- $\alpha, 35$ for IL- $1 \beta$, and 37 for uric acid) (Table 1 ).

Sample size estimates for a study with one or two interim analyses (Pocock method, setting alpha-error $=2.94 \%$ and $2.21 \%$ respectively), in addition to the final analysis, are presented in Table 1 ; this design would reduce study participants' exposure to an inferior or useless treatment. 
Table 1. Sample size estimates for a treatment arm for 3-month variations of peripheral biomarkers of oxidative stress and inflammation.

\begin{tabular}{|c|c|c|c|c|c|c|c|}
\hline & \multirow[t]{3}{*}{ Baseline } & \multirow{4}{*}{$\begin{array}{l}\text { Adj. Coeff. } \\
\text { (3-Month } \\
\text { Variation) }\end{array}$} & \multirow{3}{*}{$\begin{array}{c}\text { SD } \\
\text { (3-Month Variation) } \\
\end{array}$} & \multicolumn{4}{|c|}{$\begin{array}{c}\text { Sample Size } \\
\text { (70\% Treatment Effect) }\end{array}$} \\
\hline & & & & \multirow{2}{*}{$\begin{array}{c}\text { One Primary } \\
\text { Outcome }\end{array}$} & \multirow{2}{*}{$\begin{array}{c}\text { Two Primary } \\
\text { Outcomes }\end{array}$} & \multicolumn{2}{|c|}{ Interim Analyses (Pocock Method } \\
\hline & & & & & & One Interim & Two Interim \\
\hline & & & & $5 \%$ alpha & $2.5 \%$ alpha & $2.94 \%$ alpha & $2.21 \%$ alpha \\
\hline \multicolumn{8}{|c|}{ Markers of scavenging activity } \\
\hline Uric acid (mg/dL) & $4.670 \pm 0.566$ & $0.123 *$ & 0.117 & 29 & 37 & 15 & 11 \\
\hline Bilirubin (mg/dL) & $1.466 \pm 0.268$ & 0.066 & 0.190 & 265 & 323 & 134 & 98 \\
\hline \multicolumn{8}{|c|}{ Markers of oxidative damage } \\
\hline CellROX cells (\%) & $76.405 \pm 9.348$ & $-9.925 *$ & 11.25 & 41 & 52 & 21 & 15 \\
\hline CellROX cells (MFI) & $2605.320 \pm 828.707$ & $-523.308 *$ & 1124.538 & 148 & 181 & 75 & 55 \\
\hline Protein carbonyls (nmol/mg) & $2.976 \pm 1.402$ & -0.266 & 1.393 & 878 & 1066 & 444 & 326 \\
\hline 8-OHdG (ng/mL) & $6.379 \pm 1.140$ & -0.630 * & 0.708 & 40 & 51 & 20 & 15 \\
\hline \multicolumn{8}{|l|}{ Markers of inflammation } \\
\hline EGF (pg/mL) & $6.597 \pm 12.877$ & -3.637 & 8.513 & 175 & 214 & 89 & 65 \\
\hline Eotaxin (pg/mL) & $116.432 \pm 46.800$ & $-18.669 *$ & 31.968 & 94 & 116 & 47 & 35 \\
\hline Basic-FGF (pg/mL) & $53.218 \pm 282.165$ & -2.736 & 4.863 & 101 & 124 & 51 & 38 \\
\hline G-CSF (pg/mL) & $80.445 \pm 48.370$ & -4.692 & 61.503 & 5498 & 6667 & 2783 & 2041 \\
\hline GM-CSF (pg/mL) & $5.791 \pm 4.953$ & -1.751 * & 2.524 & 66 & 82 & 34 & 25 \\
\hline $\mathrm{HGF}(\mathrm{pg} / \mathrm{mL})$ & $64.959 \pm 77.650$ & $-26.397^{*}$ & 33.925 & 53 & 66 & 27 & 20 \\
\hline IFN- $\alpha(\mathrm{pg} / \mathrm{mL})$ & $80.869 \pm 469.445$ & 1.780 & 11.498 & 1335 & 1618 & 676 & 496 \\
\hline $\operatorname{IFN}-\gamma(\mathrm{pg} / \mathrm{mL})$ & $2.311 \pm 1.952$ & $-1.526^{*}$ & 1.937 & 52 & 64 & 26 & 19 \\
\hline $\mathrm{IL}-1 \alpha(\mathrm{pg} / \mathrm{mL})$ & $4.427 \pm 6.477$ & $-2.460 *$ & 2.526 & 34 & 43 & 17 & 13 \\
\hline IL-1 $\beta(\mathrm{pg} / \mathrm{mL})$ & $1.694 \pm 7.274$ & -1.188 & 1.096 & 27 & 35 & 14 & 10 \\
\hline IL-1RA (pg/mL) & $33.085 \pm 39.824$ & -10.464 & 18.329 & 98 & 121 & 50 & 36 \\
\hline IL-2 (pg/mL) & $20.979 \pm 107.943$ & 5.099 & 14.090 & 244 & 298 & 124 & 91 \\
\hline
\end{tabular}


Table 1. Cont.

\begin{tabular}{|c|c|c|c|c|c|c|c|}
\hline & \multirow[t]{3}{*}{ Baseline } & \multirow{4}{*}{$\begin{array}{l}\text { Adj. Coeff. } \\
\text { (3-Month } \\
\text { Variation) }\end{array}$} & \multirow{3}{*}{$\begin{array}{c}\text { SD } \\
\text { (3-Month Variation) } \\
\end{array}$} & \multicolumn{4}{|c|}{$\begin{array}{c}\text { Sample Size } \\
\text { (70\% Treatment Effect) }\end{array}$} \\
\hline & & & & \multirow{2}{*}{$\begin{array}{l}\text { One Primary } \\
\text { Outcome }\end{array}$} & \multirow{2}{*}{$\begin{array}{c}\text { Two Primary } \\
\text { Outcomes }\end{array}$} & \multicolumn{2}{|c|}{ Interim Analyses (Pocock Method } \\
\hline & & & & & & One Interim & Two Interim \\
\hline & & & & $5 \%$ alpha & $2.5 \%$ alpha & $2.94 \%$ alpha & $2.21 \%$ alpha \\
\hline $\mathrm{IL}-2 \mathrm{R}(\mathrm{pg} / \mathrm{mL})$ & $105.950 \pm 61.462$ & $-29.971 *$ & 11.182 & 4 & 8 & 2 & 2 \\
\hline IL-3 (pg/mL) & $202.849 \pm 1283.170$ & 28.661 & 4.276 & 1 & 3 & 0 & 0 \\
\hline IL-4 (pg/mL) & $4.421 \pm 11.691$ & $3.883 *$ & 3.317 & 23 & 30 & 12 & 9 \\
\hline $\mathrm{IL}-5(\mathrm{pg} / \mathrm{mL})$ & $8.177 \pm 33.861$ & -12.890 & 2.069 & 1 & 3 & 0 & 0 \\
\hline IL-6 (pg/mL) & $62.945 \pm 363.131$ & 5.559 & 3.671 & 14 & 19 & 7 & 5 \\
\hline IL-7 (pg/mL) & $12.871 \pm 40.625$ & -16.428 & 5.639 & 4 & 7 & 2 & 1 \\
\hline IL-8 (pg/mL) & $12.095 \pm 7.422$ & -11.418 & 9.425 & 22 & 28 & 11 & 8 \\
\hline IL-9 (pg/mL) & $2.248 \pm 4.814$ & $-3.749 *$ & 4.212 & 40 & 51 & 20 & 15 \\
\hline IL-10 (pg/mL) & $1079.590 \pm 6456.040$ & 1615.546 & 2417.951 & 72 & 89 & 36 & 27 \\
\hline IL-12 (pg/mL) & $58.932 \pm 110.51$ & 2.498 & 14.365 & 1058 & 1284 & 536 & 393 \\
\hline IL-13 (pg/mL) & $1.714 \pm 3.341$ & $3.732 *$ & 1.628 & 6 & 9 & 3 & 2 \\
\hline IL-15 (pg/mL) & $117.149 \pm 673.398$ & 21.693 & 21.658 & 32 & 40 & 16 & 12 \\
\hline IL-17A (pg/mL) & $1.460 \pm 2.265$ & -0.453 & 0.941 & 138 & 169 & 70 & 51 \\
\hline IL-17F (pg/mL) & $35.954 \pm 86.735$ & $-68.854 *$ & 72.039 & 35 & 44 & 18 & 13 \\
\hline IL-22 (pg/mL) & $250.425 \pm 642.791$ & -8.406 & 40.134 & 729 & 886 & 369 & 271 \\
\hline IP-10 (pg/mL) & $26.279 \pm 16.844$ & 5.699 & 30.460 & 914 & 1110 & 463 & 339 \\
\hline MCP-1 (pg/mL) & $232.083 \pm 79.633$ & 39.540 & 96.247 & 190 & 232 & 96 & 70 \\
\hline MIG (pg/mL) & $32.386 \pm 13.580$ & -5.409 & 13.555 & 201 & 245 & 102 & 75 \\
\hline MIP-1 $\alpha(\mathrm{pg} / \mathrm{mL})$ & $7.830 \pm 11.718$ & $-5.327 *$ & 5.338 & 32 & 41 & 16 & 12 \\
\hline MIP-1 $\beta(\mathrm{pg} / \mathrm{mL})$ & $182.476 \pm 1024.490$ & 17.125 & 17.060 & 32 & 40 & 16 & 12 \\
\hline RANTES (pg/mL) & $1739.970 \pm 1475.350$ & $-2331.281 *$ & 2041.081 & 25 & 32 & 12 & 9 \\
\hline
\end{tabular}


Table 1. Cont.

\begin{tabular}{|c|c|c|c|c|c|c|c|}
\hline & \multirow[t]{3}{*}{ Baseline } & \multirow{4}{*}{$\begin{array}{l}\text { Adj. Coeff. } \\
\text { (3-Month } \\
\text { Variation) }\end{array}$} & \multirow[t]{3}{*}{$\begin{array}{c}\text { SD } \\
\text { (3-Month Variation) }\end{array}$} & \multicolumn{4}{|c|}{$\begin{array}{c}\text { Sample Size } \\
\text { (70\% Treatment Effect) }\end{array}$} \\
\hline & & & & \multirow{2}{*}{$\begin{array}{l}\text { One Primary } \\
\text { Outcome }\end{array}$} & \multirow{2}{*}{$\begin{array}{l}\text { Two Primary } \\
\text { Outcomes }\end{array}$} & \multicolumn{2}{|c|}{ Interim Analyses (Pocock Method) } \\
\hline & & & & & & One Interim & Two Interim \\
\hline & & & & $5 \%$ alpha & $2.5 \%$ alpha & $2.94 \%$ alpha & $2.21 \%$ alpha \\
\hline TNF- $\alpha(\mathrm{pg} / \mathrm{mL})$ & $2.725 \pm 4.310$ & $-1.795 *$ & 1.608 & 26 & 33 & 13 & 10 \\
\hline VEGF (pg/mL) & $0.619 \pm 0.777$ & $-0.398^{*}$ & 0.519 & 54 & 68 & 28 & 20 \\
\hline
\end{tabular}

Table shows absolute values of biomarkers of oxidative stress and inflammation at the baseline visit. Adjusted beta-coefficients (adj. coeff.) of 3-month variation for each laboratory measure were obtained with mixed-effect linear regression models (including age, gender, disease duration, baseline EDSS, and duration of Interferon- $\beta 1$ a treatment prior to study inclusion as covariates; creatinine was also included for uric acid analyses) ${ }^{*}$ indicates $\left.p<0.05\right)$. Standard deviation (SD) was calculated from the variation of each laboratory measure after 3 months. Sample size per treatment arm is reported, hypothesizing a $70 \%$ treatment effect, compared with the observed effect, over 3 months (power was set at $80 \%$, alpha-error was set at 3 months. Sample size per treatment arm is reported, hypothesizing a 70\% treatment effect, compared with the observed effect, over 3 months (power was set at $80 \%$, alpha-error was set at
$5 \%$ ). Then, we also performed calculations hypothesizing additional scenarios: (i) two different biomarkers were included as combined primary outcome measures for sample size $5 \%$ ). Then, we also performed calculations hypothesizing additional scenarios: (i) two different biomarkers were included as combined primary outcome measures for sample size
estimates (alpha-error was set at 2.5\%); (ii) the study was designed to include one or two interim analyses in addition to the final analysis in order to obtain early evidence of inferior or useless treatment (alpha-error was set to be 0.0294 and 0.0221 , respectively, according to the Pocock method). Abbreviations: intracellular ROS production (CellROX), mean fluorescence intensity (MFI), 8-hydroxy-2-deoxyguanosine (8-OHdG), epidermal growth factor (EGF), eotaxin, basic-fibroblast growth factor (FGF), granulocyte-colony stimulating factor (G-CSF), granulocyte-macrophage colony-stimulating factor (GM-CSF), hepatocyte growth factor (HGF), interferon (IFN)- $\alpha$, IFN- $\gamma$, interleukin (IL)- $1 \alpha$, IL-1 $\beta$, IL-1RA, IL-2, IL-2R, IL-3, IL-4, IL-5, IL-6, IL-7, IL-8, IL-9, IL-10, IL-12, IL-13, IL-15, IL-17A, IL-17F, IL-22, IFN- $\gamma$-inducible protein (IP)-10, monocyte chemoattractant protein (MCP)-1, monokine induced by IFN- $\gamma$ (MIG), macrophage inflammatory proteins (MIP)- $1 \alpha$, MIP- $1 \beta$, regulated on activation-normal T cell expressed and secreted (RANTES), tumor necrosis factor (TNF)- $\alpha$, and vascular endothelial growth factor (VEGF). 


\section{Discussion}

Peripheral biomarkers of inflammation, scavenging activity, and oxidative damage gave realistically achievable sample size estimates, and could be used in exploratory clinical trials and observational studies to screen new or already existing medications with putative effects on inflammation and oxidative stress over a 3-month period. Not least, interim analyses could detect an inferior or useless treatment even earlier, with subsequent study termination or treatment switch within adaptive designs [12].

Current sample size calculations were rather conservative. In particular, in the Results (Section 3) and in Figure 1, we specifically focused on a 70\% treatment effect, which was smaller than what we actually observed (100\% treatment effect) [6,9]. However, greater treatment effects could be hypothesized with different medications and doses, leading to even smaller sample size estimates. Also, the inclusion of multiple markers as primary outcome measures would remain feasible for sample size calculations. Of note, present estimates are based on the combination of subcutaneous high-dose Interferon- $\beta 1 \mathrm{a}\left(\right.$ Rebif $^{\circledR}, 44$ mcg, Merck, Rome, Italy) and Coenzyme Q10. For a subgroup of patients $(50 \%)$, the Interferon- $\beta 1$ a treatment was also administered prior to study inclusion. Drug naïve patients were equally distributed between Coenzyme Q10 treatment groups, and we also included the duration of the Interferon- $\beta 1$ a treatment as a covariate in the statistical models, but, of course, we cannot exclude the possibility that previous treatment has affected the study outcomes. However, if we assume Interferon- $\beta 1$ a could have exerted its effects before inclusion in the study, we would have observed smaller Coenzyme Q10-related effects, resulting in subsequently more conservative sample size estimates. Interferon- $\beta 1 \mathrm{a}$ is an approved treatment for MS, with a well-established long-term efficacy and safety profile [13]. On the contrary, Coenzyme Q10 has proven effect on biomarkers of oxidative stress and inflammation and on MS symptoms [14-16], but its disease-modifying effect remains to be established. As such, future studies should evaluate the reproducibility of our findings on more recent medications (e.g., cladribine).

Most promising inflammatory biomarkers are strongly related to MS pathogenesis, and in particular, to acute (e.g., IL-1 $\beta$, IL-3) and chronic inflammation (e.g., IL-2R, IL-6, IL-7, IL-8, TNF- $\alpha$ ) within the central nervous system [17-21], to suppression of the activity of microglia toward brain repair (i.e., RANTES), and to neuroprotective modulation of pathologically-active macrophages and microglia (e.g., IL-4, IL-13) [17,22]. Markers of oxidative stress also resulted in rather small sample sizes, with particular regard to markers of serum scavenging activity (uric acid), and of oxidative damage in inflammatory cells and DNA (CellROX, \%, and 8-OHdG). Biomarkers of oxidative stress and inflammation are not only related to MS pathogenesis [17,23], but are also clinically relevant to MS, being associated with MS risk and progression [6,17,21,24-26], and also being used as therapeutic targets [17]. For instance, IL-6, IL-8, and RANTES have been associated with the risk of clinical relapses [27], radiological activity (e.g., lesions, atrophy) [28], treatment switch, and disability progression after up to 6 years [20]. Interestingly, clinical associations might be particularly sound in patients in apparent clinical stability [29]. As such, longitudinal measurements of oxidative stress and inflammation can provide pathologically and clinically relevant information in MS observational studies and clinical trials.

Of note, for some inflammatory biomarkers (e.g., IL-3 and IL-5) sample size estimates were unexpectedly low and should be interpreted with caution. If we assume we are studying a compound with a specific molecular target (e.g., anti-TNF- $\alpha$ or anti-CD20 antibodies), then only a very small sample is necessary to detect biological effect [30,31]. On the contrary, for compounds with multimodal mechanisms of action, a larger sample would be needed or, at least, profiles of inflammatory pathology should be considered [26].

Limitations of this study include possible confounding factors. In our previous study, we excluded patients with possible confounding factors (e.g., contraceptive and immunosuppressive medication), we used within-patients comparison of treatments (minimizing confounding effects by removing any natural biological variation), and we accounted for a number of covariates in our statistical models [6], but factors influencing oxidative stress and inflammation are multiple and virtually impossible to 
exclude completely. For instance, four patients presented with a clinical relapse $(6.6 \%)$ that we did not account for considering that patients were equally distributed in the Coenzyme-Q10-treated and untreated groups. Specificity of peripheral biomarkers to MS-related pathology remains to be further investigated, and based on current knowledge, these markers cannot replace conventional biomarkers of disability (e.g., neuroimaging) [32]. We included 180 measurements at three timepoints from 60 patients to estimate coefficients of variation for sample estimates. As such, included sample could have been larger, but was based on sample size calculations from our previous study, and not least, was in line with previous studies with similar goals $[6,8,33]$. Also, measurements over short intervals may be prone to increased measurement errors leading to a greater variability and larger sample, but apparently, this was not the case in our cohort. A control group (untreated or treated with a medication different from Interferon- $\beta 1 \mathrm{a}$ ) was unfortunately not available, with difficulties in drawing formal conclusions on the observed effects.

\section{Conclusions}

In conclusion, peripheral biomarkers of oxidative stress and inflammation could be used in exploratory, proof-of-concept studies aiming to evaluate the activity profile of new or already existing medications. Medications with putative anti-oxidant and anti-inflammatory effects could be tested in a short time ( 3 months) and on small samples ( $<30$ per treatment arm) by using a limited subset of biomarkers, before being moved toward larger and more expensive clinical trials.

Author Contributions: M.M., A.C. and V.B.M. conceived and designed the experiments; R.L., F.C., T.M., G.M. and R.P. performed the experiments; M.M., R.L., R.P. and V.B.M. analyzed the data; A.C., F.C., T.M. and G.M. contributed reagents/materials/analysis tools; M.M., A.C., R.L., F.C., T.M., G.M., R.P. and V.B.M. wrote the paper.

Funding: This research was partially supported by Merck S.p.A. (Italy), an affiliate of Merck KGaA, Darmstadt, Germany. The sponsor preliminarily approved the study design, and after independent data collection, analysis, and interpretation, approved the final version of the manuscript, which was subsequently sent to all co-authors for final approval.

Conflicts of Interest: Marcello Moccia has received research grants from MAGNIMS-ECTRIMS, United Kingdom and Northern Ireland MS Society, and Merck; and honoraria from Biogen, Sanofi-Genzyme, and Merck. Roberta Lanzillo has received honoraria from Almirall, Biogen, Novartis, Sanofi-Genzyme, Merck, and Teva. Fortunata Carbone is supported by the Ministero della Salute (grant no. GR-2016-02363725). Giuseppe Matarese is supported by the Fondazione Italiana Sclerosi Multipla (grant no. 2016/R/18), and Telethon (grant no. GGP17086), and has received research grants from Merck, Biogen, Novartis, and IBSA. Vincenzo Brescia Morra is supported by FISM (Fondazione Italiana Sclerosi Multipla) (cod. 2017/R/5) and financed or co-financed with the " 5 per mille" public funding, and has received honoraria from Almirall, Bayer, Biogen, Novartis, Sanofi-Genzyme, Merck, Mylan, and Teva.

\section{References}

1. Tur, C.; Moccia, M.; Barkhof, F.; Chataway, J.; Sastre-Garriga, J.; Thompson, A.J.; Ciccarelli, O. Assessing treatment outcomes in multiple sclerosis trials and in the clinical setting. Nat. Rev. Neurol. 2018, 14, 75-93. [CrossRef]

2. Thompson, A.J.; Baranzini, S.E.; Geurts, J.; Hemmer, B.; Ciccarelli, O. Multiple sclerosis. Lancet 2018, 391, 1622-1636. [CrossRef]

3. Zaratin, P.; Comi, G.; Coetzee, T.; Ramsey, K.; Smith, K.; Thompson, A.; Panzara, M. Progressive MS Alliance Industry Forum: Maximizing Collective Impact to Enable Drug Development. Trends Pharmacol. Sci. 2016, 37, 808-810. [CrossRef]

4. Haider, L.; Zrzavy, T.; Hametner, S.; Höftberger, R.; Bagnato, F.; Grabner, G.; Trattnig, S.; Pfeifenbring, S.; Brück, W.; Lassmann, H. The topograpy of demyelination and neurodegeneration in the multiple sclerosis brain. Brain 2016, 139, 807-815. [CrossRef]

5. Friese, M.A.; Schattling, B.; Fugger, L. Mechanisms of neurodegeneration and axonal dysfunction in multiple sclerosis. Nat. Rev. Neurol. 2014, 10, 225-238. [CrossRef] 
6. Moccia, M.; Capacchione, A.; Lanzillo, R.; Carbone, F.; Micillo, T.; Perna, F.; De Rosa, A.; Carotenuto, A.; Albero, R.; Matarese, G.; et al. Coenzyme Q10 supplementation reduces peripheral oxidative stress and inflammation in Interferon-Beta1a treated multiple sclerosis. Ther. Adv. Neurol. Disord. 2019, 12, 1-12. [CrossRef]

7. Sedgwick, P. What is a crossover trial? BMJ 2014, 348, 9-10. [CrossRef]

8. Altmann, D.R.; Jasperse, B.; Barkhof, F.; Beckmann, K.; Filippi, M.; Kappos, L.D.; Molyneux, P.; Polman, C.H.; Pozzilli, C.; Thompson, A.J.; et al. Sample sizes for brain atrophy outcomes in trials for secondary progressive multiple sclerosis. Neurology 2009, 72, 595-601. [CrossRef]

9. Moccia, M.; Prados, F.; Filippi, M.; Rocca, M.A.; Valsasina, P.; Brownlee, W.J.; Zecca, C.; Gallo, A.; Rovira, A.; Gass, A.; et al. Longitudinal spinal cord atrophy in multiple sclerosis using the generalised boundary shift integral. Ann. Neurol. 2019. [CrossRef]

10. Li, G.; Taljaard, M.; Van den Heuvel, E.R.; Levine, M.A.; Cook, D.J.; Wells, G.A.; Devereaux, P.J.; Thabane, L. An introduction to multiplicity issues in clinical trials: The what, why, when and how. Int. J. Epidemiol. 2017, 46, 746-755. [CrossRef]

11. Pocock, S. Group sequential methods in the design and analysis of clinical trials. Biometrika 1977, 64, 191-199. [CrossRef]

12. Fox, R.; Chataway, J. Advancing Trial Design in Progressive Multiple Sclerosis. Mult. Scler. 2017, 23, 1573-1578. [CrossRef]

13. Moccia, M.; Palladino, R.; Carotenuto, A.; Saccà, F.; Russo, C.V.; Lanzillo, R.; Brescia Morra, V. A 8-year retrospective cohort study comparing Interferon- $\beta$ formulations for relapsing-remitting multiple sclerosis. Mult. Scler. Relat. Disord. 2018, 19, 50-54. [CrossRef]

14. Sanoobar, M.; Eghtesadi, S.; Azimi, A.; Khalili, M.; Khodadadi, B.; Jazayeri, S.; Gohari, M.R.; Aryaeian, N. Coenzyme Q10 supplementation ameliorates inflammatory markers in patients with multiple sclerosis: A double blind, placebo, controlled randomized clinical trial. Nutr. Neurosci. 2015, 18, 169-176. [CrossRef]

15. Sanoobar, M.; Eghtesadi, S.; Azimi, A.; Khalili, M.; Jazayeri, S.; Gohari, M.R. Coenzyme Q10 supplementation reduces oxidative stress and increases antioxidant enzyme activity in patients with coronary artery disease. Int. J. Neurosci. 2013, 123, 776-782. [CrossRef]

16. Sanoobar, M.; Dehghan, P.; Khalil, M.; Azimi, A.; Seifar, F. Coenzyme Q10 as a treatment for fatigue and depression in multiple sclerosis patients: A double blind randomized clinical trial. Nutr. Neurosci. 2016, 19, 138-143. [CrossRef]

17. Göbel, K.; Ruck, T.; Meuth, S.G. Cytokine signaling in multiple sclerosis: Lost in translation. Mult. Scler. J. 2018, 24, 432-439. [CrossRef]

18. Lee, P.W.; Xin, M.K.; Pei, W.; Yang, Y.; Lovett-Racke, A.E. IL-3 Is a Marker of Encephalitogenic T Cells, but Not Essential for CNS Autoimmunity. Front. Immunol. 2018, 9, 1-7. [CrossRef]

19. Lin, C.-C.; Edelson, B.T. New Insights into the Role of IL-1 $\beta$ in Experimental Autoimmune Encephalomyelitis and Multiple Sclerosis. J. Immunol. 2017, 198, 4553-4560. [CrossRef]

20. Bassi, M.S.; Iezzi, E.; Landi, D.; Monteleone, F.; Gilio, L.; Simonelli, I.; Musella, A.; Mandolesi, G.; De Vito, F.; Furlan, R.; et al. Delayed treatment of MS is associated with high CSF levels of IL-6 and IL-8 and worse future disease course. J. Neurol. 2018, 265, 2540-2547. [CrossRef]

21. Tavakolpour, S. Interleukin 7 receptor polymorphisms and the risk of multiple sclerosis: A meta-analysis. Mult. Scler. Relat. Disord. 2016, 8, 66-73. [CrossRef]

22. Guglielmetti, C.; Le Blon, D.; Santermans, E.; Salas-Perdomo, A.; Daans, J.; De Vocht, N.; Shah, D.; Hoornaert, C.; Praet, J.; Peerlings, J.; et al. Interleukin-13 immune gene therapy prevents CNS inflammation and demyelination via alternative activation of microglia and macrophages. Glia 2016, 64, 2181-2200. [CrossRef]

23. Hu, W.T.; Howell, J.C.; Ozturk, T.; Gangishetti, U.; Kollhoff, A.L.; Hatcher-Martin, J.M.; Anderson, A.M.; Tyor, W.R. CSF Cytokines in Aging, Multiple Sclerosis, and Dementia. Front. Immunol. 2019, 10, 480. [CrossRef]

24. Moccia, M.; Lanzillo, R.; Palladino, R.; Russo, C.; Carotenuto, A.; Massarelli, M.; Vacca, G.; Vacchiano, V.; Nardone, A.; Triassi, M.; et al. Uric acid: A potential biomarker of multiple sclerosis and of its disability. Clin. Chem. Lab. Med. 2015, 53, 753-759. [CrossRef] 
25. Moccia, M.; Lanzillo, R.; Costabile, T.; Russo, C.; Carotenuto, A.; Sasso, G.; Postiglione, E.; De Luca Picione, C.; Vastola, M.; Maniscalco, G.T.; et al. Uric acid in relapsing-remitting multiple sclerosis: A 2-year longitudinal study. J. Neurol. 2015, 262, 961-967. [CrossRef]

26. Magliozzi, R.; Howell, O.; Nicholas, R.; Cruciani, C.; Castellaro, M.; Romualdi, C.; Rossi, S.; Pittieri, M.; Benedetti, M.; Gajofatto, A.; et al. Inflammatory intrathecal profiles and cortical damage in multiple sclerosis. Ann. Neurol. 2018, 83, 739-755. [CrossRef]

27. Lanzillo, R.; Carbone, F.; Quarantelli, M.; Bruzzese, D.; Carotenuto, A.; De Rosa, V.; Colamatteo, A.; Micillo, T.; De Luca Picione, C.; Saccà, F.; et al. Immunometabolic profiling of patients with multiple sclerosis identifies new biomarkers to predict disease activity during treatment with interferon Interferon beta-1a. Clin. Immunol. 2017, 183, 249-253. [CrossRef]

28. Ziliotto, N.; Bernardi, F.; Jakimovski, D.; Baroni, M.; Bergsland, N.; Ramasamy, D.P.; Weinstock-Guttman, B.; Zamboni, P.; Marchetti, G.; Zivadinov, R.; et al. Increased CCL18 plasma levels are associated with neurodegenerative MRI outcomes in multiple sclerosis patients. Mult. Scler. Relat. Disord. 2018, 25, 37-42. [CrossRef]

29. Ghezzi, L.; Cantoni, C.; Cignarella, F.; Bollman, B.; Cross, A.H.; Salter, A.; Galimberti, D.; Cella, M.; Piccio, L. T cells producing GM-CSF and IL-13 are enriched in the cerebrospinal fluid of relapsing MS patients. Mult. Scler. 2019, 1352458519852092. [CrossRef]

30. Gibellini, L.; De Biasi, S.; Bianchini, E.; Bartolomeo, R.; Fabiano, A.; Manfredini, M.; Ferrari, F.; Albertini, G.; Trenti, T.; Nasi, M.; et al. Anti-TNF- $\alpha$ drugs differently affect the TNF $\alpha$-sTNFR system and monocyte subsets in patients with psoriasis. PLoS ONE 2016, 11, 1-16. [CrossRef]

31. Ellrichmann, G.; Bolz, J.; Peschke, M.; Duscha, A.; Hellwig, K.; Lee, D.H.; Linker, R.A.; Gold, R.; Haghikia, A. Peripheral CD19 + B-cell counts and infusion intervals as a surrogate for long-term B-cell depleting therapy in multiple sclerosis and neuromyelitis optica/neuromyelitis optica spectrum disorders. J. Neurol. 2019, 266, 57-67. [CrossRef] [PubMed]

32. Moccia, M.; de Stefano, N.; Barkhof, F. Imaging outcomes measures for progressive multiple sclerosis trials. Mult. Scler. 2017, 23, 1614-1626. [CrossRef] [PubMed]

33. Cawley, N.; Tur, C.; Prados, F.; Plantone, D.; Kearney, H.; Abdel-Aziz, K.; Ourselin, S.; Wheeler-Kingshott, C.A.M.G.; Miller, D.H.; Thompson, A.J.; et al. Spinal cord atrophy as a primary outcome measure in phase II trials of progressive multiple sclerosis. Mult. Scler. 2018, 24, 932-941. [CrossRef] [PubMed]

(C) 2019 by the authors. Licensee MDPI, Basel, Switzerland. This article is an open access article distributed under the terms and conditions of the Creative Commons Attribution (CC BY) license (http://creativecommons.org/licenses/by/4.0/). 